\title{
Commentary: Emotional Problems and Depression among Children and Adolescents in Today's Society
}

\author{
Clarissa Agee Shavers \\ The Safer Tomorrows: Injury Prevention and Violence Reduction Project ${ }^{\odot}$, Primary Care Office, Detroit, USA \\ Email: ageeclar@gmail.com
}

Received 29 March 2014; revised 2 May 2014; accepted 10 May 2014

Copyright (c) 2014 by author and Scientific Research Publishing Inc.

This work is licensed under the Creative Commons Attribution International License (CC BY).

http://creativecommons.org/licenses/by/4.0/

(c) ()

\section{Abstract}

Clinical diagnoses of emotional problems and depression are serious global health care issues among children and adolescents in today's society. Global estimates of the prevalence of childhood and adolescent emotional problems and depression have been found to be growing worldwide. Anxiety and mood disorders are very common emotional problems or disorders identified among this population. Similarly, major depressive disorder (MDD) is now considered one of the most common diagnoses among children and adolescents with the first depressive episode generally identified in late childhood or early adolescence. Likewise, co-morbid disorders including emotional problems have been found to significantly impact the psycho-social-emotional and mental health status of children and adolescents. Routine screening and assessment for emotional problems and depression among children and adolescents has been recommended for Health Care Providers (HCP's) in clinical settings. However, many children and adolescents are not routinely screened and unfortunately this results in missed or under-diagnosing. For these reasons, raising the awareness of HCP's in clinical practice regarding these issues may significantly improve routine screening, early detection, and treatment efforts among children and adolescents. A synopsis of the current literature including implications for clinical practice, research, and evidence-based intervention is discussed.

\section{Keywords}

Emotional Problems, Depression, Children, Adolescents, Health Care Providers (HCP's)

\section{Introduction}

Emotional problems (including anxiety, mood disorders, emotional distress) and depression are not uncommon

How to cite this paper: Shavers, C. A. (2014). Commentary: Emotional Problems and Depression among Children and Adolescents in Today's Society. Open Journal of Depression, 3, 74-87. http://dx.doi.org/10.4236/ojd.2014.32012 
mental health problems identified among children and adolescents today in society (Martin-Merino, Ruigómez, Wallender, Johansson, \& Garcia-Rodriguez, 2010; Collishaw, Maughan, Natarajan, \& Pickles, 2010; Harpin, Kenyon, Kools, Bearinger, \& Ireland, 2013; Thaper, Collishaw, Pine, \& Thaper, 2012). Studies of mental health among children and adolescents demonstrated that 1) anxiety and mood disorders among children and adolescents are prevalent conditions that may become chronic, and may place children and adolescents at risk for current and later functional impairment (Centers for Disease Control (CDC), 2011); 2) comorbid anxiety disorders are common in youth with bipolar disorder (BP), and most often predate BP onset (Sala et al., 2010); 3) out-ofhome placement and homeless youth are equally at risk for mental health issues including a high level of mental health distress and lower levels of protective factors compared to other youth (Harpin et al., 2013); 4) unipolar depressive disorder in adolescence is common worldwide, often unrecognized, and the burden is deemed to be the highest in low-income and middle-income countries (Thaper et al., 2012); and 5) one in five adolescents experience significant symptoms of emotional distress and nearly one in ten are emotionally impaired (Knopf, Park, \& Mulye, 2008).

Similarly, studies have shown that parent-reported child and adolescent (youth) mental health problems and youth self-reports of emotional problems and depression were found to be significantly prevalent among children and adolescents (Ghandour, Kogan, Blumberg, Jones, \& Perrin, 2012; Pastor, Reuben, \& Duran, 2012). Investigators identified that parent-reported emotional and behavioral health conditions affected a substantial minority of United States of America (USA) children and families with nearly 3.9 million 6 to 17 years old having ever been diagnosed with anxiety or depression and 2.7 million having a current or former behavioral or conduct-related diagnosis (Ghandour et al., 2012). However, in an empirical study examining three measures that identified children (aged 4 to 17 years) per parent-report with emotional and behavioral problems in the USA, the investigators found that the prevalence of parent-reported children emotional and behavioral problems and sociodemographic characteristics, diagnosed developmental conditions, and service use of children with problems depended on the measure of emotional and behavioral problems (Pastor, Reuben, \& Duran, 2012). Likewise, many investigators found that children and adolescent (youth) self-reports tended to coincide with the previously cited high prevalence of emotional problems and depression noted in today's society (Chavira, Garland, Daley, \& Hough, 2008; Atilola, Balhara, Stevanovic, Avicenna, \& Kandemir, 2013; Sabri, Coohey, \& Campbell, 2012; Völlink, Bolman, Eppingbroek, \& Dehue, 2013). In summary, the results from several youth self-reported studies revealed that 1) anxiety disorder comorbid with a physical illness was associated with more severe levels of emotional problems as well as greater functional impairment than that having an anxiety disorder or physical illness alone; and greater total problems in general, particularly internalizing problems, as well as more somatic complaints and higher levels of anxiety and depression (Chavira et al., 2008); 2) conduct and emotional problems were identified as the most prevalent mental health problem for a sample of 1894 adolescents from five developing countries (Atilola et al., 2013); 3) adolescents (11 - 18 years) who were identified as having multiple types of victimization experiences were more likely to have co-occurring mental health problems than adolescents who self-reported single type of victimization experiences (Sabri et al., 2012); and 4) investigators discovered that of the 325 children ( $18.8 \%$ bullied by mobile phone $\& 24.1 \%$ via internet) surveyed, a) depression correlated positively with health complaints and both correlated positively with the duration of cyberbullying and b) girls were more often victims of cyberbullying than boys (Völlink et al., 2013).

In the same way, adolescent depression has been found to significantly predict young adult depression as a result of adolescent depression co-morbidity including adolescent oppositional defiant disorder, anxiety, and substance disorders (Copeland, Shanahan, Costello, \& Angold, 2009). Moreover, sexual minority youths, who may be defined by sexual identity or by the sex of their contacts, have specific health needs and are at disproportionate risk for certain health care problems including emotional disturbance and depression (CDC, 2011). Similarly, help-seeking behaviour remains a problem in the management of depression in ethnic minority populations, partly due to stigma associated with mental illness (although this may be changing due to acculturation), and differing illness beliefs (Ahmed \& Bhugra, 2007). Also, adolescent and young adult male health still today has been noted to receive little attention, despite the potential for positive effects on adult quality and length of life, reduction of health disparities and social inequalities and young men are substantially less likely than their female peers to have private health insurance or to be eligible for public coverage (Bell, Breland, \& Ott, 2013; Gold, Sonfield, Richards, \& Frost, 2009).

According to the Diagnostic and Statistical Manual of Mental Disorders, $4^{\text {th }}$ edition, Text Revision (DSM-IV-TR), major depressive episode (MDE) is typically defined as a period of at least two weeks during 
which there is either depressed mood or the loss of interest or pleasure in nearly all activities (American Psychiatric Association, 2000). In children and adolescents, the depressed mood may be irritable rather than sad (American Psychiatric Association, 2000). Further, researchers have shown that baseline MDE significantly predicted subsequent generalized anxiety disorder (GAD) onset but not persistence (Kessler, Gruber, Hettema, Hwang, Sampson, \& Yonkers, 2008). Equally, findings have shown that adolescent depression is associated with a range of adverse later outcomes including poor physical and mental health, problems in social functioning, and suicidality (Maughan, Collishaw, \& Stringaris, 2012).

Further, costs associated with childhood mental disorders include medical expenses, special education needs, burden to the criminal justice system, and social services (Merikangas, Nakamura, \& Kessler, 2009). In addition, depression is a common, treatable disorder with high costs for individuals and society (European Communities, 2008). Still, depression and other mental disorders often go undiagnosed in adolescence despite the availability of screening tools proven effective in identifying adolescent depression during the primary care visit (National Institute for Health Care Management (NIHCM Foundation), 2010). Presently, the US Preventive Services Task Force (USPSTF) (2009) recommends only screening adolescents (12 - 18 years of age) for clinical depression and screening may only occur when appropriate systems are in place to ensure accurate diagnosis, treatment, and follow-up care (2009).

However, in a separate recommendation, the USPSTF found insufficient evidence to assess the balance of benefits and harms of screening children 7 to 11 years of age for clinical depression (2009). Nevertheless, children can be exposed to many types of trauma including inflicted trauma, unintentional trauma, natural disasters, war and neighborhood violence, child sexual abuse (Forman-Hoffman et al., 2013; Chou, 2012; Senn, Carey, \& Vanable, 2010). For there is scientific evidence that children who self-reported child sexual assault (CSA) acknowledged depression, anxiety disorders, and suicide ideation (Fergusson, Boden, \& Horwood, 2008; Wherry, Baldwin, Junco, \& Floyd, 2013) whereas, adolescents, adults and older adults who reported CSA were more likely to report depression, binge drinking, recent marijuana use, partner violence, and diagnoses of mixed anxiety and depression, generalized anxiety disorder, posttraumatic stress disorder (PTSD), and suicidal ideation (Felitti et al., 1998; Senn et al., 2010; Chou, 2012). Thus, conducting routine screening, assessing and referrals for emotional problems and depression among children and adolescents in clinical settings including primary care, sexually transmitted disease (STD) and family planning clinics may assist in minimizing the number of undetected cases, underdiagnosising, undertreatment, and possibly the numerous costs associated with diagnoses of emotional trauma and depression among children and adolescents (NICHM Foundation, 2010; European Communities, 2010; Williams, O’Connor, Eder, \& Whitlock, 2009; Rhodes, Sciberras, Oberklaid, South, Davies, \& Efron, 2012; Friedman, Sadhu, \& Jellinek, 2012; Senn et al., 2010; Schwarz, 2010; Hirth \& Berenson, 2012; Merikangas et al., 2009).

The purpose of this commentary is four-fold to: 1) provide a brief background on the scope of the problem, epidemiology and prevalence from a global perspective. 2) Highlight key issues and concerns relating to the diagnoses of emotional problems and depression among children and adolescents. 3) Discuss the implications of routine screening, assessment and referral for emotional problems and depression among children and adolescents by HCP's in clinical settings including primary care, STD, and family planning clinics. 4) Hopefully, further raise consciousness among HCP's concerning the impact of emotional problems and depression among children and adolescents today in our society.

\section{Scope of the Problem}

Mental disorders including emotional problems and depression among children are an important public health issue due to their prevalence, early onset, and significant impact on child, family, and community (CDCa, 2013). All demographic groups are affected by mental disorders in childhood, however, investigators have noted that the prevalence estimates vary by all demographic groups (i.e. found that boys were more likely to die by suicide than girls) (CDCa, 2013). Also, scientists found that parents of children born very preterm with clinically significant mental health problems were two and a half times more likely to have children who were classified as being "at risk" for dysregualtion (social-emotional development) problems (Treyvaud et al., 2010). Similarly, researchers have identified that emotion dysregulation signifies an intrapersonal mechanism linking stress to poor mental health outcomes among adolescents (McLaughlin \& Hatzenbuehler, 2009).

More, most mental health problems diagnosed in adulthood begin in adolescence (Knopf et al., 2008). Too, 
the most common mental health disorders among adolescents include depression, anxiety disorders and attention-deficit/hyperactivity disorder and substance abuse (Knopf et al., 2008). Another important fact, especially among working age youth or adolescents with mental health disorders, is that there is an overlap between functional decline, mental disorders, risk of economically inactive status and the adverse effects of an economically inactive status (BMJ, 2013). In essence, working age youth with mental health disorders, may also be at risk for adverse effects as a result of an economically inactive status (BMJ, 2013).

In addition, the risk of suicide is greatly increased by depression and other psychological disorders (NIHCM Foundation, 2010). Results from the National 2011 Youth Risk Behavior Surveillance (YRBS) conducted in the USA revealed that many high school students were noted to engage in behaviors that place them at risk for the leading causes of morbidity and mortality including suicide (CDC, 2012). For example, during the 12 months before the survey, $28.5 \%$ of students nationwide had felt so sad or hopeless almost every day for 2 or more weeks in a row that they stopped doing some usual activities (CDC, 2012). More astounding, nationwide, 15.8\% of students had seriously considered attempted suicide during the 12 months before the survey (CDC, 2012).

Another study identified that in 2011, death rates among adolescents' ages 15 - 19 years, suicide accounted for 22 percent of injury deaths (Federal Interagency Forum on Child and Family Statistics, 2013). Moreover, a recent study acknowledged that among adolescents (11 - 15 years of age) surveyed in five countries revealed that youth engaged in physical fighting and weapon carrying were at risk for physical and emotional health outcomes (Walsh et al., 2013). Key findings from Walsh et al. (2013) study revealed that boys reported more frequent episodes of fighting/weapon carrying and medically attended injuries in every country, while girls reported more health emotional symptoms including severe emotional problems. Further, investigators discovered that the risk of suicidal ideation was 2.4 times greater among youth who experienced peer victimization in the past year, 3.4 times greater among those who were sexually assaulted, and 4.4 times greater among those exposed to maltreatment, relative to children who were not exposed to these types of victimization (Turner, Finkelhor, Shattuck, \& Hamby, 2012).

Comparably, results of a public school nurse workforce survey revealed that two-thirds of the survey respondents had provided emergency management (adolescent behavioral health emergencies) in the prior school year for child abuse or neglect, depression, and exposures to school violence (Ramos, Greenberg, Sapien, BauerCreegan, Hine, \& Geary, 2013). Also, over $40 \%$ of the public school nurse workforce survey respondents stated they had provided emergency management for a suicidal student in the prior school year (Ramos et al., 2013). Likewise, during the 30 days prior to the YRBS survey, $38.7 \%$ of the adolescents surveyed had drunk alcohol and 23.1\% had used marijuana (CDC, 2012). Also, statistically significant lower mean total emotional self-efficacy (ESE) ratings were found for adolescents who self-reported physical fighting, lifetime alcohol use and sexual intercourse with genders of $60 \%$ boys and $40 \%$ girls; and African Americans or Blacks comprising $54 \%$ and Caucasians or Whites $46 \%$ of the study population (Valois \& Zullig, 2013).

Moreover, ethnic groups have been found to differ in rates of suicidal behaviors among youths, the context within which suicidal behavior occurs, and patterns of help-seeking (Goldston et al., 2008). Also, among diverse ethnic youth groups there appears to be an importance of religion and spirituality, stigma associated with mental health difficulties, including suicidality, and often with help-seeking; differences by racial/ethnic youth groups for youth-family relationship and youth-school relationship in relations to predictors of adolescent depression (Goldston et al., 2008; Moon \& Rao, 2010). In another related study, the investigators examined the relationship between perceived discrimination by adults and peers in the school setting and depressive symptoms in a sample of ( $\mathrm{N}=95)$ racial minority immigrant-origin adolescents (13 to 19 years) attending an urban high school (Tummala-Narra \& Claudius, 2013). Tummala-Narra and Claudius (2013) study findings revealed that girls reported higher levels of depressive symptomatology than boys, although the relationship between perceived discrimination and depressive symptoms was significant for both boys and girls. It is important to note that both foreignborn and US-born groups in this study reported experiencing racial and ethnic discrimination by adults and peers at school.

\section{Epidemiology}

The World Health Organization (WHO) (2013a) has deemed that mental, neurological and substance use disorders are major contributors to morbidity and premature mortality throughout the world. Many mental disorders begin in childhood-adolescence and have significant adverse effects on subsequent role transitions (Kessler et al., 
2011). Mental disorders are among the most common causes of disability (United States Department of Health and Human Services (USDHHSa), 2013). Also, recently it has been projected that over the next 20 years, noncommunicable diseases (NCD's) will cost more than US \$30 trillion, and mental health conditions alone will account for the loss of an additional US \$16.1 trillion, with a predicted dramatic impact on quality of life and productivity (Bloom et al., 2011).

Equally, health systems have not yet adequately responded to the burden of mental disorders; as a consequence, the gap between the need for treatment and its provision is large all over the world (WHO, 2013b). According to the WHO, between $76 \%$ and $85 \%$ of people with severe mental disorders receive no treatment for their disorder in low-income and middle-income countries; and the corresponding range for high-income countries is also high: between 35\% and 50\% (2013b). Globally, for example, annual spending on mental health is less than US \$2.00 per person and less than US \$0.25 per person in low-income countries, with $67 \%$ of these financial resources allocated to stand-alone mental hospitals, despite their cited association with poor health outcomes and human rights violations (WHO, 2013b). Likewise, reimbursement for behavioral health services in pediatric primary cares settings presently exist as a barrier and thus significantly impact the integration of behavioral health services into routine health maintenance activities for the pediatric population [children and adolescents] (Talmi \& Fazio, 2012).

Also, depression is commonly referred to as a chronic, personally debilitating mental illness that can affect day-to-day functioning of children and adolescents and their relationships with others (Rao \& Chen, 2009; Trowell, 2011). Children and adolescents with chronic diseases are also known to have a significant rate of comorbidity with depression (Herzer \& Hood, 2010; Osborn, Berg, Hughes, Pham, \& Wiebe, 2013; Kotrotsiou et al., 2011). In addition, the diagnosis of depression was found to be significantly correlated with lesions as a result of childhood traumatic brain injury (TBI) according to a study conducted by Max et al. and colleagues (2011). The investigators found that non-anxious depression was significantly correlated with only left hemisphere lesions specifically lesions of the left inferior frontal gyrus (IFG) and left temporal pole (Max et al., 2011). Whereas, among the children participants anxious depression was significantly correlated with right frontal white matter lesions and with left parietal lesions (Max et al., 2011). Other significant findings from this study included family history of anxiety disorder was related to new-onset depression (combined non-anxious and anxious depression), as well as, to anxious depression although not to non-anxious depression; family history of mood disorder was not related to new-onset depression; and older age at injury was significantly related to new onset depression (all) and to non-anxious depression, but not to anxious depression (Max et al., 2011).

In another similarly related study, investigators tested the hypothesis that the association between irritability and depression is accounted for by genetic factors. Data from the G1219 study, a UK twin/sibling sample ( $\mathrm{N}=$ 2651), were used in a cross-sectional and longitudinal design (Stringaris et al., 2012). Study findings revealed that a significantly stronger phenotypic relationship existed with depression than with delinquency and headstrong/hurtful behaviors were more strongly related to delinquency than to depression (Stringaris et al., 2012). Also, investigators found that scores on the irritability scale were significantly higher in girls than in boys and respectively; and scores on the headstrong/hurtful behavior scale were significantly higher in boys than in girls respectively (Stringaris et al., 2012).

Likewise, findings revealed that in a clinical sample of young women from low-income households, racial/ ethnic differences in the level of depressive symptoms existed and that life circumstances, such as trauma and PTSD symptoms, may have contributed to these differences (Hirth \& Berenson, 2012). In summary, the investigators identified that African Americans reported a higher score for sadness than White or Hispanic women, White women and Hispanic women reported higher scores for self-failure than African American women, White women reported higher scores for self-dislike than both African Americans and Hispanics, and White women reported higher scores for self-criticism than African Americans and almost one fourth (23.9\%) of the women reported a score of $\geq 4$ on the Beck Depression Inventory for Primary Care (BDI-PC) (Hirth \& Berenson, 2012). Alike, depression (including present, previous or past history) in females has been found to be more prevalent during their reproductive years, and many have theorized that hormonal changes during various reproductive periods, including during and after pregnancy or postpartum, may play a significant role in the development of depression (Goodwin, 2009; USDHHSb, 2009; Vesga-López et al., 2008). Thus, children and adolescent females who become pregnant may be at-high risk for depression (USDHHSb, 2009; Pinzon \& Jones, 2012; VesgaLópez et al., 2008). 


\section{Clinical Relevance}

Emotional problems and depression among children and adolescents can occur at any age, in some cases starting in children as early as infancy (Keren \& Tyano, 2006). The etiology of depression among children and adolescents appears to involve a complex interplay among genetic, neurobiological, cognitive, interpersonal, and environmental factors in concert with developmental factors (Rao \& Chen, 2009). Likewise, an interplay or significant symptom overlap has been found to exist between sleep disturbance, anxiety, and depression among children (Chorney, Detweiler, Morris, \& Kuhn, 2008). Also, with diagnoses of anxiety and depression, children and adolescents may have medical co-morbidities, such as, diabetes and asthma (Helgeson, Siminerio, Escobar, \& Becker, 2009; Chiang, Ma, Huang, Tseng, \& Hsueh, 2009; Herzer \& Hood, 2010; Osborn et al., 2013; Kotrotsiou et al., 2011).

Depressive episodes may commonly last anywhere from a few months to many years (Duckworth \& Shelton, 2012). The depressive symptoms that a depressed teen may exhibit can range from complaints about stomach aches to fights with family and friends, skipping school, getting poor grades, or substance use and irritability (Cheung \& Ewigman, 2009). Thus, to judge the extent of a child or adolescent impairment, you need to assess overall functioning and ask about school, home, friends, and leisure activities (Cheung \& Ewigman, 2009). Also, it is important to remember that children and adolescents are able to report on their feelings and are often better informants about their internal state than others (Korczak, 2012). Nevertheless, a high index of suspicion is needed, as children have limited ways in which to express their distress (Korczak, 2012).

What's more, it has been denoted that normal interaction and children's strong mental health depend on parents and children communicating with one another (Bornstein, 2013). While poor or ineffective communication and lack of support has been identified by a study among Chinese American adolescents as negative influences on their psychosocial health (Yuwen \& Chen, 2012). Similarly, in a United Nations Children's Fund (UNICEF) (2013) comparative overview study of child well-being in 29 of the world's most advanced economies the investigators for this study found that among children and adolescents ages 11, 13, and 15 that in every country, children and adolescents reported it to be more difficult to talk to their fathers than to their mothers-and the gap between the two measures were, on average, 16 percentage points (2013). Also, relationships measured via self-report of well-being by the study youth participants 1) find it easy to talk to their mothers, 2) find it easy to talk to their fathers, and 3) find their classmates kind and helpful that Canada, France and the USA were the only countries ranked in the bottom group for all three relationships (UNICEF, 2013).

These study findings underscore the importance of communication and the possible delay in the early identification, treatment, and referral of mental health concerns among children and adolescents if interactions between significant others and/or lack of communication are ineffectual (Yuwen \& Chen, 2012; UNICEF, 2013). Also, peer and family support may protect against depression among children and adolescents (Moon \& Rao, 2010). Researchers have examined the association between adolescents' relationship with family and school and depressive symptoms across ethnic/racial groups (Moon \& Rao, 2010). Significant results from the study revealed that youth-family relationship and youth-school relationship were significant predictors of adolescent depression and that youths' good relationship with family and school were associated with lower depressive symptoms (Moon \& Rao, 2010).

Alike, unmet growth/developmental tasks of childhood and adolescence may significantly impact the potential or actual risks commonly associated with youth who self-report emotional problems/or depression in the clinical setting (Cooper, Masi, \& Vick, 2009; CDCb, 2013). For example, children and youth in preschool and elementary school with mental health problems are more likely to experience problems at school, be absent, or be suspended or expelled than are children with other disabilities (Stagman \& Cooper, 2010). Also, rates of firsttime mental health service utilization have been found to increase around significant transitional periods for children and adolescents (i.e. formal school entry, transitions to middle school and junior high school) (Erath, Keiley, Pettit, Lansford, Dodge, \& Bates, 2009). However, children and adolescents with mental health problems who have access to quality health care and comprehensive age-appropriate mental health screens and assessments have improved health and development (Children’s Defense Fund, 2010; Cooper et al., 2009; American Psychological Association, 2008).

That's why, when screening and assessing for emotional problems and depression in the clinical setting, if a positive screen occurs, HCP's also should evaluate for anxiety and mood disorders, as well as for the presence of other psychiatric disorders including psychotic symptoms or co-existing bipolar II condition for these may 
contribute to depressed children and adolescent functional impairment (Sala et al., 2010; Polanczyk et al., 2010; Parker, 2013). Another important area to screen for is early sexual initiation among the children and adolescents (McLeod \& Knight, 2010). For empirical findings have shown that youth who had engaged in early sexual initiation or prior to 15 years of age had a significantly higher average level of socioemotional problem (depression and dependency) at age 10 - 11 than youth who had initiated sex at older ages (McLeod \& Knight, 2010). Also, many children and youth may have a subthreshold depressive disorder that may not necessarily meet all of the DSM-IV Revised criteria for a major affective disorder, but may have risk factors and require intervention (Klein, Shankman, Lewinsohn, \& Seeley, 2009).

In addition, HCP's should routinely screen and conduct an assessment for the presence of any suicide ideation and suicide attempts among children and adolescents. For, children and adolescents at high risk-for suicide 1) those with a plan or recent suicide attempt with high probability of lethality, 2) stated current intent to kill themselves, or 3) recent suicidal ideation or behavior may need inpatient psychiatric admission (Jain, Jain, \& Islam, 2012). Whereas, children and adolescents with fewer risk factors, esp. those who want help and have social support, hope for the future, and a desire to resolve conflicts, may require only a brief crisis-oriented intervention (Jain et al., 2012). Meanwhile, sometimes individuals become so discouraged and hopeless that death seems preferable to life (Duckworth \& Shelton, 2012). These feelings can lead to suicidal ideation, attempts and death by suicide (Duckworth \& Shelton, 2012). With those most at risk of suicide being young people who are socially isolated, being abused, or exploited (Roberts, Pryke, \& Murphy, 2013). In these cases, in an attempt to alleviate these vulnerable feelings, the hope box could be used as a concrete and feasible intervention (Joiner \& Riberio, 2011). The hope box is a technique that has the potential to take possibly the edge off of burdensomeness and alienation (Joiner \& Riberio, 2011). The hope box should be tailored so that it specifically contains items that contradict perceptions of burdensomeness and social alienation (Joiner \& Riberio, 2011). Also, clinicians or HCP's may wish to routinely assess for burdensomeness and social isolation in an effort to early identify feelings of burdensomeness and social alienation among this vulnerable population (Joiner \& Riberio, 2011).

Further, HCP's should evaluate for substance abuse usage and substance-related disorders among children and adolescents with emotional problems and depression and generate appropriate referrals (Substance Abuse and Mental Health Services Administration (SAMHSA), 2013; Wu et al., 2011). Importantly, investigators identified that in one study of 12 - 17 years old adolescents that close to 1/4th of adolescent alcohol or drug users met DSM-IV criteria for a substance-related disorder and users of marijuana, heroin, cocaine, or sedatives demonstrated an elevated rate of abuse or dependence on these drugs (Wu et al., 2011). Also, need to evaluate for exposures to violence and trauma among children and adolescents with emotional problems and depression (Shavers, 2013; Forman-Hoffman et al., 2013; American Psychological Association (APA), 2008). For findings have shown that 1 ) exposures to violence and trauma may result in mild-moderate-severe psycho-social-emotional and mental health concerns among children and adolescents and 2) approximately 2/3's of children and adolescents will experience at least one traumatic event which may require child [adolescent] trauma interventions (Shavers, 2013; APA, 2008; Forman-Hoffman et al., 2013).

Similarly, researchers identified that perceived racial/ethnic inequities at the community level in general by survey respondents were consistently associated with less perceived availability of healthcare services for children and adolescents and if communities were perceived as "very segregated", the survey respondents were significantly less likely to say that young children have "lots of availability" to access primary care, specialty care, and mental health services (Davis et al., 2012). Disparities in access to mental health care services for minority youth or youth of color continues to exist today and needs to be further addressed (Alegria, Vallas, \& Pumariega, 2010). Also, inadequate screening of young children prevents recognition of emotional, social, and behavioral problems (Cooper et al., 2009). However, primary care including STD and family planning clinics which provide services to prevent, screen for, and treat diseases and conditions such as depression, sexually transmitted infections (STI's), as well as address issues of violence (i.e. intimate partner violence) and trauma have been found to benefit both female and male [children and adolescents] clients who visit these clinics or settings (SAMHSA, 2011; Kavanaugh \& Anderson, 2013; Smith, Buzi, \& Weinman, 2010; Gold, 2011).

Nevertheless, there are many promising empirical findings or interventions that have found to be or possibly be beneficial in promoting the mental health of children and adolescents diagnosed with emotional problems and depression (Davydov, Stewart, Ritchie, \& Chaudieu, 2010; Lewandowski et al., 2013; Rothon et al., 2010; Beardslee et al., 2013; Children's Defense Fund, 2010). Among some of those promising empirical findings or 
interventions include 1) incorporating the concept of resilience (defense mechanism) which enables people to thrive in the face of adversity and thus, improving resilience among children and adolescents with emotional problems and mental disorders may be an important aim for treatment and prophylaxis therapy (Davydov et al., 2010). 2) The development and usage of a care pathway and quality indicators (QI's) for the primary and specialty care management of adolescent depression from case identification through symptom remission (Lewandowski et al., 2013). 3) Across-sectional association was identified between physical activity and depressive symptoms for both boys and girls at baseline, with a decrease in the odds of depressive symptoms of about 8\% for each additional hour of exercise undertaken per week (Rothon et al., 2010). 4) Similarly, adolescent offspring of depressed parents are at high risk for experiencing depressive disorders themselves and may benefit from long-term group cognitive behavior prevention (CBP) program and/or medication (Beardslee et al., 2013; Children's Defense Fund, 2010). Furthermore, it is important to remember that the quality of health outcomes for children, adolescents and their families is improved through the translation of empirical findings and the integration of evidence into practice, as well as, improving the quality of care including preventive health for child and adolescent mental health problems within primary care, STD, or family planning clinics (Christian, 2013; Sayal et al., 2012; Wood et al., 2013; Polaha, Dalton, \& Allen, 2011; Gold, Sonfield, Richards, \& Frost, 2009).

\section{Summary}

Child and adolescent mental health problems including emotional problems and depression are common in primary healthcare including STD and family planning clinics (Sayal et al., 2012; Senn et al., 2010; SAMHSA, 2011; Smith et al., 2010). HCP's must be culturally responsive, sensitive and competent when assessing and screening for emotional problems and depression among children and adolescents (SAMHSA, 2011; American Psychological Association, 2008). Because emotional problems and depression among children and adolescents are serious global health care issues, with possibly early screening and assessment including identification of these disorders may assist in managing potential functional impairments (Collishaw et al., 2010; USPSTF, 2009; WHO, 2013a; WHO, 2013b). Finally, there are many promising empirical based interventions and treatments; however, there is still a need for further study on changing the trajectory of emotional problems and depression among children and adolescents from diverse, ethnic and cultural backgrounds (Davydov et al., 2010; Lewandowski et al., 2013; Rothon et al., 2010; Beardslee et al., 2013; Children’s Defense Fund, 2010; Davis et al., 2012; Alegria et al., 2010).

\section{Conclusion}

Routine screening and assessment for emotional problems and depression among children and adolescents who are deemed high-risk or at-risk, as well as, those who may or may not be at-risk is necessary and appropriate. Also, it is imperative to incorporate decisions of care for children and adolescents clinically diagnosed with emotional problems and depression based upon individual, health care and medical issues, ethnicity, culture, growth and development, and age. Thus, it is incumbent upon HCP's to be proactive screen and assess for exposures to emotional trauma including violence, co-morbidities, suicide ideation, and substance abuse among children and adolescents in primary care settings including STD and family planning clinics. For increasing awareness, due diligence by HCP's on behalf of this vulnerable population may assist in changing the present trajectory of emotional problems and depression among children and adolescent's in today's society.

\section{Acknowledgements}

This article was supported by the Text and Academic Authors Association Inc. (TAA) URL: http://www.TAAonline.net academic publication grant. Also, the author would like to acknowledge the following members of The Safer Tomorrows Research Team ${ }^{\odot}$ : C. A. Archer-Gift, Ph.D., L. M. Green, M.A., L.L.P.C., L.B.S.W., J. E. Onyskiw, Ph.D., and M. Price, Ph. D. and all the members of The Safer Tomorrows Project ${ }^{\circ}$ for their unceasing support and dedication to our mission and vision.

\section{References}

Ahmed, K., \& Bhugra, D. (2007). Depression across Ethnic Minority Cultures: Diagnostic Issues. World Cultural Psychiatry Research Review, 2, 47-56. http://www.wcprr.org/pdf/02-23/2007.0203.4756.pdf 
Alegria, M., Vallas, M., \& Pumariega, A. (2010). Racial and Ethnic Disparities in Pediatric Mental Health. Child \& Adolescent Psychiatric Clinics of North America, 19, 759-774. http://dx.doi.org/10.1016/j.chc.2010.07.001

American Psychiatric Association (2000). Diagnostic and Statistical Manual of Mental Disorders (4th ed.). Washington, DC: Author.

American Psychological Association (2008). Presidential Task Force on Posttraumatic Stress Disorder and Trauma in Children and Adolescents Children and Trauma: Update for Mental Health Professionals. Washington, DC: American Psychological Association.

Atilola, O., Balhara, Y. P. S., Stevanovic, D., Avicenna, M., \& Kandemir, H. (2013). Self-Reported Mental Health Problems among Adolescents in Developing Countries: Results from an International Pilot Sample. Journal of Developmental Behavioral Pediatrics, 34, 129-137. http://dx.doi.org/10.1097/DBP.0b013e31828123a6

Beardslee, W. R., Brent, D. A., Weersing, V. R., Clarike, G. N., Porta, G., Hollon, S. D., \& Garber, J. (2013). Prevention of Depression in At-Risk Adolescents: Longer-Term Effects. The Journal of the American Medical Association Psychiatry, 70, 1161-1170. http://dx.doi.org/10.1001/jamapsychiatry.2013.295

Bell, D. L., Breland, D. J., \& Ott, M. A. (2013). Adolescent and Young Adult Male Health: A Review. Pediatrics, 132, 535546. http://dx.doi.org/10.1542/peds.2012-3414

Bloom, D. E., Cafiero, E. T., Jané-Llopis, E., Abrahams-Gessel, S., Bloom, L. R., Fathima, S., \& Weinstein, C. (2011). The Global Economic Burden of Noncommunicable Diseases. Geneva, Switzerland: World Economic Forum.

British Medical Journal (BMJ) (2013). Adolescents and Young Adults Not in Employment, Education or Training (NEET): Their Problems Are More Than Economic. British Medical Journal, 237, f5270.

Bornstein, M. H. (2013). Parenting and Child Mental Health: A Cross Cultural Perspective. World Psychiatry, 12, $258-265$. http://dx.doi.org/10.1002/wps.20071

Centers for Disease Control and Prevention (CDC) (2011). Sexual Identity, Sex of Sexual Contacts, and Health-Risk Behaviors among Students in Grades 9-12-Youth Risk Behavior Surveillance, Selected Sites, United States, 2001-2009. Morbidity \& Mortality Weekly Report (MMWR) Early Release, 60, 1-133. http://www.cdc.gov/mmwr/pdf/ss/ss60e0606.pdf

Centers for Disease Control and Prevention (CDC) (2012). Youth Risk Behavior Surveillance-United States, 2011. Morbidity \& Mortality Weekly Report (MMWR), 61, 1-166. http://www.cdc.gov/mmwr/pdf/ss/ss6104.pdf.

Centers for Disease Control (CDCa) (2013). Mental Health Surveillance among Children-United States, 2005-2011. http://www.cdc.gov/mmwr/preview/mmwrhtml/su6202a1.htm?s cid=su6202a1 w

Centers for Disease Control (CDCb) (2013). Child Development, Children's Mental Health-NCBDDD. http://www.cdc.gov/ncbddd/childdevelopment/mentalhealth.html

Chavira, D. A., Garland, A. F., Daley, S., \& Hough, R. (2008). The Impact of Medical Morbidity on Mental Health and Functional Health Outcomes among Children with Anxiety Disorders. Journal of Developmental Behavioral Pediatrics, 29, 394-402. http://dx.doi.org/10.1097/DBP.0b013e3181836a5b

Cheung, A., \& Ewigman, B. (2009). Adolescent Depression: Is Your Patient Suffering in Silence? Journal of Family Practice, 58, 187-192. http://www.jfponline.com/fileadmin/jfp_archive/pdf/5804/5804JFP_Article2.pdf

Chiang, L.-C., Ma, W.-F., Huang, J.-L., Tseng, L.-F., \& Hsueh, K.-C. (2009). Effect of Relaxation-Breathing Training on Anxiety and Asthma Signs/Symptoms of Children with Moderate-to-Severe Asthma: A Randomized Controlled Trial. International Journal of Nursing Studies, 46, 1061-1070. http://dx.doi.org/10.1016/j.ijnurstu.2009.01.013 http://www.journalofnursingstudies.com/issues

Children’s Defense Fund (2010). Mental Health Fact Sheet. Washington DC: Children's Defense Fund.

Chorney, D. B., Detweiler, M. F., Morris, T. L., \& Kuhn, B. R. (2008). The Interplay of Sleep Disturbance, Anxiety, and Depression in Children. Journal of Pediatric Psychology, 33, 339-348. http://dx.doi.org/10.1093/jpepsy/jsm105 http://jpepsy.oxfordjournals.org/content/33/4/339.full.pdf+html?sio1=53cf66e8-1e72-4d03-849b-a757cd6d0ddf

Christian, B. J. (2013). Translational Research: The Imperative for Integrating Evidence into Pediatric Nursing Practice to Improve Health Outcomes. Journal of Pediatric Nursing, 28, 508-510. http://dx.doi.org/10.1016/j.pedn.2013.07.003

Chou, K.-L. (2012). Childhood Sexual Abuse and Psychiatric Disorders in Middle-Aged and Older Adults: Evidence from the 2007 Adult Psychiatric Morbidity Survey. Journal of Clinical Psychiatry, 73, e1365-e1371.

http://dx.doi.org/10.4088/JCP.12m07946 http://www.psychiatrist.com/privatepdf/2012/v73n11/v73n1102.pdf

Collishaw, S., Maughan, B., Natarajan, L., \& Pickles, A. (2010). Trends in Adolescent Emotional Problems in England: A Comparison of Two National Cohorts Twenty Years Apart. Journal of Child Psychology \& Psychiatry, 51, 885-894. http://dx.doi.org/10.1111/j.1469-7610.2010.02252.x http://onlinelibrary.wiley.com/doi/10.1111/jcpp.2010.51.issue-8/issuetoc

Cooper, J. L., Masi, R., \& Vick, J. (2009). Social-Emotional Development in Early Childhood: What Every Policymaker 
Should Know. New York: National Center for Children in Poverty (NCCP).

Copeland, W. E., Shanahan, L., Costello, J., \& Angold, A. (2009). Childhood and Adolescent Psychiatric Disorders as Predictors of Young Adult Disorders. Archives of General Psychiatry, 66, 764-772.

http://dx.doi.org/10.1001/archgenpsychiatry.2009.85

http://archpsyc.jamanetwork.com

Davis, M. M., Moseley, K. L., Woolford, S. J., Singer, D. C., Philip, J. T., Royan, R., Kauffman, A. D., et al. (2012). Health, Nutrition and Healthcare Availability. National Voices Project, Survey 2 (Report 2-Final). Ann Arbor, MI: Regents of The University of Michigan and National Voices Project. http://nationalvoicesproject.org/communications/reports

Davydov, D. M., Stewart, R., Ritchie, K., \& Chaudieu, I. (2010). Resilience and Mental Health. Clinical Psychology Review, 30, 479-495. http://dx.doi.org/10.1016/j.cpr.2010.03.003

Duckworth, K., \& Shelton, R. (2012). Depression. Arlington, VA: National Alliance on Mental Illness (N.A.M.I.). http://www.nami.org/Template.cfm?Section=Depression\&template=Contentmanagement/contentdisplay.cfm\&ContentID $=67727$

Erath, S. A., Keiley, M. K., Pettit, G. S., Lansford, J. E., Dodge, K. A., \& Bates, J. E. (2009). Behavioal Predictors of Mental Health Service Utilization in Childhood through Adolescence. Journal of Developmental Behavioral Pediatrics, 30, 481-488. http://dx.doi.org/10.1097/DBP.0b013e3181c35938

http://www.jdbp.org

European Communities (2008). Improving the Mental Health of the Population: Policy Briefs. Luxembourg: European Communities. http://ec.europa.eu/health/archive/ph_determinants/life_style/mental/docs/policy_briefs_en.pdf

Federal Interagency Forum on Child and Family Statistics (2013). America's Children: Key National Indicators of Well-Being. Washington DC: U.S. Government Printing Office.

Felliti, V. J., Anda, R. F., Nordenberg, D., Williamson, D. F., Spitz, A. M., \& Edwards, V. (1998). Relationship of Childhood Abuse and Household Dysfunction to Many of the Leading Causes of Death in Adults: The Adverse Childhood Experiences (ACE) Study. American Journal of Preventive Medicine, 14, 245-248. http://dx.doi.org/10.1016/S0749-3797(98)00017-8

Fergusson, D. N., Boden, J. M., \& Horwood, L. J. (2008). Exposure to Childhood Sexual and Physical Abuse and Adjustment in Early Adulthood. Child Abuse \& Neglect, 32, 607-619. http://dx.doi.org/10.1016/j.chiabu.2006.12.018 http://www.brown.uk.com/childabuse/fergusson.pdf

Forman-Hoffman, V., Knauer, S., McKeeman, J., Zolotor, A., Blanco, R., Lloyd, S., Viswanathan, M., et al. (2013). Child and Adolescent Exposure to Trauma: Comparative Effectiveness of Interventions Addressing Trauma other than Maltreatment or Family Violence. Comparative Effectiveness Review No. 107. Prepared by the RTI International-University of North Carolina at Chapel Hill Evidence-based Practice Center under Contract No. 290-2007-10056-1 (AHRQ Publication No. 13-EHC054-EF). Rockville, MD: Agency for Healthcare Research and Quality). http://www.ncbi.nlm.nih.gov/books/NBK126092/pdf/TOC.pdf

Friedman, N., Sadhu, J., \& Jellinek, M. (2012). DSM-5: Implications for Pediatric Mental Health Care. Journal of Developmental Behavioral Pediatrics, 33, 163-178. http://www.jdbp.org

Ghandour, R. M., Kogan, M. D., Blumberg, S. J., Jones, J. R., \& Perrin, J. M. (2012). Mental Health Conditions among School-Aged Children: Geographic and Sociodemographic Patterns in Prevalence and Treatment. Journal of Developmental Behavioral Pediatrics, 33, 42-54. http://dx.doi.org/10.1097/DBP.0b013e31823e18fd http://www.jdbp.org

Gold, R. B. (2011). The Role of Family Planning Centers as Gateways to Health Coverage and Care. Guttmacher Policy Review, 14, 15-19. http://www.guttmacher.org/pubs/gpr/14/2/gpr140215.pdf

Gold, R. B., Sonfield, A., Richards, C. L., \& Frost, J. J. (2009). Next Steps for America's Family Planning Program: Leveraging the Potential of Medicaid and Title $X$ in an Evolving Health Care System. New York: Guttmacher Institute. http://www.gutmacher.org/pubs/NextSteps.pdf

Goldston, D. B., Molock, S. D., Whitbeck, L. B., Murakami, J. L., Zayas, L. H., Hall, N., \& Gordon, C. (2008). Cultural Considerations in Adolescent Suicide Prevention and Psychosocial Treatment. American Psychologist, 63, 14-31. http://dx.doi.org/10.1037/0003-066X.63.1.14

Goodwin, G. M. (2009). Evidence-Based Guidelines for Treating Bipolar Disorder: Revised Second Edition-Recommendations from the British Association for Psychopharmacology. Journal of Psychopharmacology, 23, 346-388.

http://dx.doi.org/10.1177/0269881109102919 http://www.bap.org.uk/pdf5/Bipolar_guidelines.pdf

Harpin, S., Kenyon, D. B., Kools, S., Bearinger, L. H., \& Ireland, M. (2013). Correlates of Emotional Distress in Out-ofHome Youth. Journal of Child \& Adolescent Psychiatric Nursing, 26, 110-118. http://dx.doi.org/10.1111/jcap.12030 http://onlinelibrary.wiley/com/doi/10.111/jap.12030/pdf 
Helgeson, V. S., Simineriom L., Escobar, O., \& Becker, D. (2009). Predictors of Metabolic Control among Adolescents with Diabetes: A 4-Year Longitudinal Study. Journal of Pediatric Psychology, 34, 254-270.

http://dx.doi.org/10.1093/jpepsy/jsn079

http://jpepsy.oxfordjournals.org/content/34/3/254.full.pdf+html?sid=642e629b-d649-9648-67c668efcd71

Herzer, M., \& Hood, K. K. (2010). Anxiety Symptoms in Adolescents with Type I Diabetes: Association with Blood Glucose Monitoring and Glycemic Control. Journal of Pediatric Psychology, 35, 415-425.

http://dx.doi.org/10.1093/jpepsy/jsp063 http://jpepsy.oxfordjournals.org/content/35/4/415.full.pdf+html

Hirth, J. M., \& Berenson, A. B. (2012). Racial/Ethnic Differences in Depressive Symptoms among Young Women: The Role of Intimate Partner Violence, Trauma, and Posttraumatic Stress Disorder. Journal of Women's Health, 21, 966-974. http://dx.doi.org/10.1089/jwh.2011.3366 http://online.liebertpub.com/doi/pdfplus/10.1089/jwh.2011.3366

Jain, S., Jain, R., \& Islam, J. (2012). How to Lower Suicide Risk in Depressed Children and Adolescents. Current Psychiatry, 11, 21-31. http://www.currentpsychiaty.com/fileadmin/cp_archive/pdf/1105/1105CP_Jain.pdf

Joiner, T. E., \& Riberio, J. D. (2011). Assessment and Management of Suicidal Behavior in Teens. Psychiatric Annals, 41, 220-225. http://dx.doi.org/10.3928/00485713-20110325-05

http://www.healio.com/psychiatry/journals/psycann

Kavanaugh, M. L., \& Anderson, R. M. (2013). Contraception and Beyond: The Health Benefits of Services Provided at Family Planning Centers. New York: Guttmacher Institute. http://www.gutttmacher.org/pubs/health-benefits.pdf

Keren, M., \& Tyano, S. (2006). Depression in Infancy. Child \& Adolescent Psychiatric Clinics of North America, 15, 883897. http://www.ncbi.nlm.nih.gov/pubmed/16952766

Kessler, R. C., Aguilar-Gaxiola, S., Alonso, J., Chatterji, S., Lee, S., Ormel, J., Üstün, B., \& Wang, P. S. (2011). The Global Burden of Mental Disorders: An Update from the WHO World Mental Health (WMH) Surveys.

http://dx.doi.org/10.1017/S0033291707002012

http://www.ncbi.nlm.nih.gov/pmc/articles/PMC3039289/pdf/nihms264248.pdf

Kessler, R. C., Gruber, M., Hettema, J. M., Hwang, I., Sampson, N., \& Yonkers, K. A. (2008). Co-Morbid Major Depression and Generalized Anxiety Disorders in the National Comorbidity Survey Follow-Up. Psychological Medicine, 38, 365-374.

Klein, D. N., Shankman, S. A., Lewinsohn, P. M., \& Seeley, J. R. (2009). Subthreshold Depressive Disorder in Adolescents: Predictors of Escalation to Full-Syndrome Depressive Disorders. Journal of the American Academy of Child \& Adolescent Psychiatry, 48, 703-710.

Knopf, D., Park, M. J., \& Mulye, T. P. (2008). The Mental Health of Adolescents: A National Profile, 2008. San Francisco, CA: National Adolescent Health Information Center, University of California, San Francisco.

Korczak, D. (2012). Identifying Depression in Childhood: Symptoms, Signs and Significance. Paediatrics \& Child Health, $17,572$.

Kotrotsiou, E., Krommydas, G., Papathanasiou, I., Kotrotsiou, S., Paralikas, T., Lahana, E., \& Kiparissi, G. (2011). Ansiety and Depression in Teenagers and Young Adults with Asthma. Health Science Journal, 5, 229-236. http://www.hsj.gr/volume5/issue3/539.pdf

Lewandowski, R. E., Acri, M. C., Hoagwood, K. E., Olfson, M., Clarke, G., Gardner, W., Scholle, H. S., et al. (2013). Evidence for the Management of Adolescent Depression. Pediatrics, 132, e996-e1009.

http://dx.doi.org/10.1542/peds.2013-0600

http://pediatrics.aappublications.org/content/early/2013/09/11/peds.2013-0600.full.pdf

Martín-Merino, E., Ruigómez, A., Wallender, M. A., Johansson, S., \& García-Rodríguez, L. A. (2010). Prevalence, Incidence, Morbidity and Treatment Patterns in a Cohort of Patients Diagnosed with Anxiety in UK Primary Care. Family Practice, 27, 9-16. http://dx.doi.org/10.1093/fampra/cmp071 http://fampra.oxfordjournals.org/content/27/1/9.full.pdf+html

Maughan, B., Collishaw, S., \& Stringaris, A. (2012). Depression in Childhood and Adolescence. Journal of the Canadian Academy of Child \& Adolescent Psychiatry, 22, 35-40. http://www.ncbi.nlm.nih.gov/pmc/articles/PMC3565713/pdf/ccap22_1p0035.pdf

Max, J. E., Keatley, E., Wilde, E. A., Bigler, E. D., Schachar, R. J., Saunders, A. E., Ewing-Cobbs, L., Chapman, S. B., Dennis, M., Yang, T. T., \& Levin, H. S. (2012). Depression in Children and Adolescents in the First Six Months after Traumatic Brain Injury. International Journal of Developmental Neuroscience, 30, 239-245. http://www.ncbi.nlm.nih.gov/pmc/articles/PMC3322312/

McLaughlin, K. A., \& Hatzenbuehler, M. L. (2009). Mechanisms Linking Stressful Life Events and Mental Health Problems in a Prospective, Community-Based Sample of Adolescents. Journal of Adolescent Health, 44, 153-160.

http://dx.doi.org/10.1016/j.jadohealth.2008.06.019

McLeod, J. D., \& Knight, S. (2010). The Association of Socioemotional Problems with Early Sexual Initiation. Perspectives on Sexual \& Reproductive Health, 42, 93-101. http://dx.doi.org/10.1363/4209310

Merikangas, K. R., Nakamura, E. F., \& Kessler, R. C. (2009). Epidemiology of Mental Disorders in Children and Adoles- 
cents. Dialogues in Clinical Neuroscience, 11, 7-20.

http://www.ncbi.nlm.nih.gov/pmc/articles/PMC2807642/pdf/Dialogues/ClinNeurosci-11-7.pdf

Moon, S. S., \& Rao, U. (2010). Youth-Family, Youth-School Relationship, and Depression. Child \& Adolescent Social Work Journal, 27, 115-131. http://dx.doi.org/10.1007/s10560-010-0194-9

http://www.ncbi.nlm.nih.gov/pmc/articles/PMC2863357/

National Institute for Health Care Management (NIHCM Foundation) (2010). Improving Early Identification \& Treatment of Adolescent Depression: Considerations \& Strategies for Health Plans. NIHCM Foundation Issue Brief, Washington DC: Author. http://www.nihcm.org/pdf/Adol_MH_Issue_Brief_FINAL.pdf

Osborn, P., Berg, C. A., Hughes, A. E., Pham, P., \& Wiebe, D. J. (2013). What Mom and Dad Don’t Know Can Hurt You: Adolescent Disclosure to and Secrecy from Parents about Type I Diabetes. Journal of Pediatric Psychology, 38, 141-150. http://dx.doi.org/10.1093/jpepsy/jss102 http://jpepsy.oxfordjournals.org/content/38/2/141.full.pdf+html?sid=54a5350f-f637-4ea8-a185-430a232f2ce2

Parker, G. (2013). Teenage Depression: Some Navigational Points for Parents and Professionals. World Psychiatry, 12, 272274. http://dx.doi.org/10.1002/wps.20059 http://www.wpanet.org

Pastor, P. N., Reuben, C. A., \& Durank C. R. (2012). Identifying Emotional and Behavioral Problems in Children Aged 4-17 Years: United States, 2001-2007. National Health Statistics Reports (48), Hyattsville, MD: National Center for Health Statistics.

Pinzon, J. L., \& Jones, V. F. (2012). Care of Adolescent Parents and Their Children. Pediatrics, 130, e1743-e1756. http://dx.doi.org/10.1542/peds.2012-2879

http://pediatrics.aappublications.org/content/130/6/e1743.full.pdf+html?sid=7415d6b3-eb98-41a1-973b-5cd0ade4e675

Polaha, J., Dalton III, W. T., \& Allen, S. (2011). The Prevalence of Emotional and Behavior Problems in Pediatric Primary Care Serving Rural Children. Journal of Pediatric Psychology, 36, 652-660. http://dx.doi.org/10.1093/jpepsy/jsq116 http://jpepsy.oxfordjournals.org/content/36/6/652.full.pdf+html?sid=0162fc48-671d-4c6f-ae55-e20e6d643c57.

Polanczyk, G., Moffitt, T. E., Arseneault, L., Cannon, M., Ambler, A., Richard, S., et al. (2010). Etiological and Clinical Fea- tures of Childhood Psychotic Symptoms. Archives of General Psychiatry, 67, 328-338. http://dx.doi.org/10.1001/archgenpsychiatry.2010.14 http://archpsyc.jamanetwork.com

Rao, U., \& Chen, L. A. (2009). Characteristics, Correlates, and Outcomes of Childhood and Adolescent Depressive Disorders. Dialogues in Clinical Neuroscience, 11, 45-62. http://www.ncbi.nlm.nih.gov/pmc/articles/PMC2766280/pdf/DialoguesClinNeurosci-11-45.pdf

Ramos, M. M., Greenberg, C., Sapien, R., Bauer-Creegan, J., Hine, B., \& Geary, C. (2013). Behavioral Health Emergencies Managed by School Nurses Working with Adolescents. Journal of School Health, 83, 712-717. http://dx.doi.org/10.1111/josh.12085 http://onlinelibrary.wiley.com/doi/10.1111/josh.12085/pdf

Rhodes, A., Sciberras, E., Oberklaid, F., South, M., Davies, S., \& Efron, D. (2012). Unmet Developmental, Behavioral, and Psychosocial Needs in Children Attending Pediatric Outpatient Clinics. Journal of Developmental Behavioral Pediatrics, 33, 469-478. http://dx.doi.org/10.1097/DBP.0b013e31825a70e6 http://www.jdbp.org

Roberts, J. H., Pryke, R., \& Murphy, M. (2013). Young People Who Self Harm by Cutting. British Medical Journal, 347, f5250. http://dx.doi.org/10.1136/bmj.f5250

Rothon, C., Edwards, P., Bhui, K., Viner, R. M., Taylor, S., \& Stansfield, S. A. (2010). Physical Activity and Depressive Symptoms in Adolescents: A Prospective Study. BMC Medicine, 8, 32. http://www.biomedcentral.com/content/pdf/1741-7015-8-32.pdf

Sabri, B., Coohey, C., \& Campbell, J. (2012). Multiple Victimization Experiences, Resources, and Co-Occurring Mental Health Problems among Substance-Using Adolescents. Violence \& Victims, 27, 744-763. http://dx.doi.org/10.1891/0886-6708.27.5.744 http://www.ncbi.nlm.nih.gov/pmc/articles/PMC3506025/pdf/nihms419635.pdf

Sala, R., Axelson, D. A., Castro-Fornieles, J., Goldstein, T. R., Ha, W., Liao, F., et al. (2010). Comorbid Anxiety in Children and Adolescents with Bipolar Spectrum Disorders: Prevalence and Clinical Correlates. Journal of Clinical Psychiatry, 71, 1344-1350. http://dx.doi.org/10.4088/JCP.09m05845gre

Sayal, K., Amarasinghe, M., Robotham, S., Coope, C., Ashworth, M., Day, C., Tylee, A., \& Simonoff, E. (2012). Quality Standards for Child and Adolescent Mental Health in Primary Care. BMC Family Practice, 13, 51.

http://www.biomedcentral.com/1471-2296/13/51

Senn, T. E., Carey, M. P., \& Vanable, P. A. (2010). The Intersection of Violence, Substance Use, Depression, and STD’s: Testing of a Syndemic Pattern among Patients Attending an Urban STD Clinic. The Journal of the National Medical Association, 102, 614-620. http://www.ncbi.nlm.nih.gov/pmc/articles/PMC2935202/pdf/nihms231007.pdf

Schwarz, S. W. (2010). Adolescent Reproductive and Sexual Health: Facts for Policymakers. (Fact Sheet). New York: National Center for Children in Poverty. http://www.nccp.org/publications/pdf/text_931.pdf 
Shavers, C. A. (2013). Exposures to Violence and Trauma among Children and Adolescents. Health, 5, $298-305$.

Smith, P. B., Buzi, R. S., \& Weinman, M. L. (2010). Mental Health Screening in Family-Planning Clinics: A Sexual RiskReduction Opportunity. Journal of Sex \& Marital Therapy, 36, 181-192. http://dx.doi.org/10.1080/00926231003719475

Stagman, S., \& Cooper, J. L. (2010). Children's Mental Health: What Every Policymaker Should Know. (Brief). New York: The National Center for Children in Poverty (N.C.C.P.). http://www.nccp.org/publications/pdf/text_929.pdf.

Stringaris, A., Zavos, H., Leibenluft, E., Maughan, B., \& Eley, T. C. (2012). Adolescent Irritability: Phenotypic Associations and Genetic Links with Depressed Mood. American Journal of Psychiatry, 169, 47-54.

http://dx.doi.org/10.1176/appi.ajp.2011.10101549

http://ajp.psychiatryonline.org/data/Journals/AJP/4396/appi.ajp.2011.1010549.pdf

Substance Abuse and Mental Health Services Administration (SAMHSA) (2013). Results from the 2012 National Survey on Drug Use and Health: Summary of National Findings (NSDUH Series H-46, HHS Publication No. (SMA) 13-4795). Rockville, MD: Author.

Substance Abuse and Mental Health Services Administration (SAMHSA) (2011). Identifying Mental Health and Substance Use Problems of Children and Adolescents: A Guide for Child-Serving Organizations (HHS Publication No. SMA 124670). Rockville, MD: Author.

http://www.samhsa.gov/children/508compliant_Identifying_MH_and_SU_Problems_1-30-2012.pdf.

Talmi, A., \& Fazio, E. (2012). Commentary: Promoting Health and Well-Being in Pediatric Primary Care Settings: Using Health and Behavior Codes at Routine Well-Child Visits. Journal of Pediatric Psychology, 37, 496-502.

http://dx.doi.org/10.1093/jpepsy/jss047

http://jpepsy.oxfordjournals.org/content/37/5/496.full.pdf+html?sid=ddfe6408-15ez-4a85-88c6-b797c44fa8d2

Trowell, J., \& Miles, G. (2011). Childhood Depression: A Place for Psychotherapy. London: Karnac Books.

Treyvaud, K., Anderson, V. A., Lee, K. J., Woodward, L. J., Newnham, C., Inder, T. E., Doyle, L. W., \& Anderson, P. J. (2010). Parental Mental Health and Early Social-Emotional Development of Children Born Very Preterm. Journal of Pediatric Psychology, 35, 768-777. http://dx.doi.org/10.1093/jpepsy/jsp109 http://jpepsy.oxfordjournals.org/content/35/7/768.full.pdf+html?sid=04e9509e-e640-47be-84b6-da11dc6861e4

Tummala-Narra, P., \& Claudius, M. (2013). Perceived Discrimination and Depressive Symptoms among Immigrant-Origin Adolescents. Cultural Diversity and Ethnic Minority Psychology, 19, 257-269. http://dx.doi.org/10.1037/a0032960

Turner, H. A., Finkelhor, D., Shattuck, A., \& Hamby, S. (2012). Recent Victimization Exposure and Suicidal Ideation in Adolescents. Archives of Pediatric \& Adolescent Medicine, 166, 1149-1154.

http://archpedi.jamanetwork.com

United Nations Children's Fund (UNICEF) Office of Research (2013). Child Well-Being in Rich Countries: A Comparative Overview, Innocenti Report Card 11. Florence: UNICEF Office of Research. http://www.unicef-irc.org/publications/pdf/rc11 eng.pdf.

United States Department of Health and Human Services (USDHHSa) (2013). Mental Health and Mental Disorders. Healthy People 2020. http://www.healthypeople.gov/2020/topicsobjectives2020/overview.aspx?topicid=28

United States Department of Health and Human Services (USDHHSb), National Institute of Mental Health, National Institute of Health (2009). Women and Depression: Discovering Hope (NIH Publication No. 09 4779). Washington, DC: Author.

http://www.nimh.nih.gov/health/publications/women-and-depresion-discovering-hope/depression-what-every-woman-sho uld-know.pdf

United States Preventive Services Task Force (U.S.P.S.T.F.) (2009). Task Force Recommends Screening Adolescents for Clinical Depression. Research Activities, May 2009, No. 345, Rockville, MD: Agency for Healthcare Research and Quality. http://archive.ahrq.gov/news/research-activiites/may09/0509RA1.html

Valois, R. F., \& Zullig, K. J. (2013). Psychometrics of a Brief Measure of Emotional Self-Efficacy among Adolescents from the United States. Journal of School Health, 83, 704-711. http://dx.doi.org/10.1111/josh.12084

http://onlinelibrary.wiley.com/doi/10.1111/josh.12084/pdf

Vesga-López, O., Blanco, C., Keyes, K., Olfson, M., Grant, B. F., \& Hasin, D. S. (2008). Psychiatric Disorders in Pregnant and Postpartum Women in the United States. Archives of General Psychiatry, 65, 805-815. http://dx.doi.org/10.1001/archpsyc.65.7.805 http://archpsyc.jamanetwork.com

Völlink, T., Bolman, C. A. W., Eppingbroek, A., \& Dehue, F. (2013). Emotion-Focused Coping Worsens Depressive Feelings and Health Complaints in Cyberbullied Children. Journal of Criminology, 2013, Article ID: 416976. http://dx.doi.org/10.1155/2013/416976 http://www.hindawi.com/journals/jcrim/2013/416976/

Walsh, S. D., Molcho, M., Craig, W., Harel-Fisch, Y., Huynh, Q., Kukaswadia, A., et al. (2013). Physical and Emotional Health Problems Experienced by Youth Engaged in Physical Fighting and Weapon Carrying. PLoS ONE, 8, Article ID: e56403. http://www.plosone.org 
Wherry, J. N., Baldwin, S., Junco, K., \& Floyd, B. (2013). Suicidal Thoughts/Behaviors in Sexually Abused Children. Journal of Child Sexual Abuse, 22, 534-551. http://dx.doi.org/10.1080/10538712.2013.800938

Williams, S. B., O’Connor, E. A., Eder, M., \& Whitlock, E. P. (2009). Screening for Child and Adolescent Depression in Primary Care Settings: A Systematic Evidence Review for the US Preventive Services Task Force. Pediatrics, 123, e716e733. http://dx.doi.org/10.1542/peds.2008-2415 http://pediatrics.aappublications.org/content/123/4e716.full.html

Wood, S., Goldberg, D., Beeson, T., Bruen, B., Johnson, K., Mead, H., et al. (2013). Health Centers and Family Planning: Results of a Nationwide Study. Washington DC: The George Washington University School of Public Health \& Health Services Department of Health Policy.

http://sphhs.gwu.edu/departments/healthpolicy/publication/Health Centers and Family Planing.pdf

World Health Organization (WHO) (2013a). Investing in Mental Health: Evidence for Action. Geneva: Author. http://apps.who.int/iris/bitstream/10665/87232/1/9789241564618_eng.pdf

World Health Organization (WHO) (2013b). Mental Health Action Plan 2013-2020. Geneva: Author. http://apps.who.int/iris/bitstream/10665/89966/1/978924150602_eng.pdf

Wu, L. T., Woody, G. E., Yang, C., Pan, J. J., \& Blazer, D. G. (2011). Racial/Ethnic Variations in Substance-Related Disorders among Adolescents in the United States. Archives of General Psychiatry, 68, 1176-1185. http://dx.doi.org/10.1001/archgenpsychiatry.2011.120 http://archpsyc.jamanetwork.com

Yuwen, W., \& Chen, A. C. C. (2013). Chinese American Adolescents: Perceived Parenting Styles and Adolescents' Psychosocial Health. International Nursing Review (INR), 60, 236-243. http://dx.doi.org/10.1111/inr.12002 http://onlinelibrary.wiley.com/doi/10.1111/inr.12002/pdf 